\title{
Recensiones
}

Jon Sobrino, Jesucristo liberador. Lectura histórico-teológica de Jesús de Nazaret. San Salvador: UCA Editores, 1991, 445 páginas / Madrid: Editorial Trotta, 1991, 350 páginas.

Jon Sobrino es autor de varios libros y de innumerables artículos sobre temáticas muy diversas (Jesús de Nazaret, Cristo, Iglesia, espiritualidad de la teología de la liberación, vida religiosa, los pobres y los pueblos crucificados como lugar teológico, el profetismo de la iglesia latinoamericana, Monseñor Romero, los mártires de El Salvador, etc.). Ha dedicado, pues, sus esfuerzos intelectuales y su pasión cristiana a elaborar una reflexión teológica que surja đe la realidad y que sirva a la mejor comprensión y trañsformación de la misma. El libro que ahora estoy presentando es una clara muestra de ello.

Jon Sobrino ya había escrito en el año 1976 una Cristología desde América latina y en 1982 un Jesús en América latina. El autor justifica en la introducción, y muy convincentemente, el por qué de un nuevo tratamiento del tema. Aduce una razón de tipo coyuntural (de hecho Jesucristo es usado en América latina para fundamentar una cosmovisión "cristiana"; es por ello necesario que la cristología presente el verdadero rostro de aquél para que "esté al servicio del mysterium liberationis y en contra del mysterium iniquitatis") y otra de tipo eclesial (toda imagen de Iglesia pretende basarse en la figura de Jesucristo; hoy, en tiempos de divisiones y desconciertos eclesiales, es más necesario que nunca presentar la imagen de Cristo más verdadera que sirva de criterio de autenticidad de la Iglesia real). Motivado por estas razones y sobre todo por la realidad de América latina (y, mutatis mutandis, del mundo entero), una realidad llena de crucificados para la que Jesucristo quiere ser buena noticia, Jon Sobrino nos ofrece la primera parte de su nueva cristología, a la que, esperamos, siga, en el tiempo más breve posible, la segunda.

Tres grandes apartados conforman el presente libro. El primero, "Método de la cristología latinoamericana", está compuesto por tres capítulos que tratan sobre la nueva imagen y la nueva fe en Cristo, sobre el lugar eclesial y social de la cristología y sobre el Jesús histórico como punto de partida de la cristología.

En el segundo, "Misión y fe de Jesús", abre la vía un original y significativo capítulo sobre la relación entre Jesús y el reino de Dios al que sigue el docu- 
mentado excurso sobre el reino de Dios en las cristologías actuales. Temas tan importantes como el del reino de Dios como lo "último", es decir, lo único definitivo, para Jesús, el del reino de Dios como la esperada utopía en medio de la miseria de la historia, el del reino de Dios destinado en último término a los pobres, el del reino de Dios expresado y señalado por las parábolas y las señales de Jesús, son el objeto de este cuarto capítulo. Los otros dos capítulos que forman este segundo apartado hablan de las relaciones entre Jesús y Dios en su vertiente más interior (la fe de Jesús, su confianza en el Padre, sus tentaciones y crisis) y exterior (la acción profética de Jesús para desenmascarar las falsas imágenes de Dios y para señalar el verdadero rostro de Dios). Cierra este segundo apartado del libro un interesante excurso sobre el Dios de vida y los ídolos de la muerte.

El último apartado del libro, "La cruz de Jesús", está dividido en cuatro capítulos llenos de sensibilidad, de pasión, de sentido existencial, de realidad. “¿Por qué matan a Jesús?”, “¿Por qué muere Jesús?”, "El Dios crucificado”, "El pueblo crucificado", son los títulos de dichos últimos capítulos; expresan estupendamente el contenido y la fuerza de cada uno de ellos.

Así acaba el primer volumen de la cristología de Jon Sobrino: con la presentación del pueblo crucificado. Como dice el autor, esto parece contradecir el mismo título del libro "Jesucristo liberador". Pero, como muy bien señala Jon Sobrino, esto no es así. Y no sólo porque el objeto del segundo volumen vaya a ser el de la buena noticia de la resurrección del crucificado y de los crucificados como principio de acción que mueva a ir bajando de la cruz a quienes están clavados en ella, sino también porque toda la praxis de Jesús, incluida su entrega hasta el final, es ya buena noticia liberadora que interpela y reta a la fe en Jesús liberador y al compromiso por la liberación al que esa fe lleva.

Estamos, pues, ante una nueva y excelente cristología. $Y$ su novedad y excelencia le vienen precisamente de que está escrita desde la realidad de las mayorías oprimidas, empobrecidas, tratadas injustamente y crucificadas, y desde una lectura existencial de los testimonios bíblicos que hablan de un Dios que es presencia en la historia dolorosa de la humanidad, que es misericordia, que es justicia salvadora y liberadora, que es compañía solidaria; todo ello mirando a una praxis existencial, en seguimiento de un Dios que nos muestra en Jesús cuál es su estilo y su línea de acción, que no son otros que el "ser liberador".

R. S.

Pedro en la iglesia primitiva, ed. Rafael Aguirre Monasterio, Estella (Navarra): Verbo Divino (Institución S. Jerónimo, 23), 1991, 258 páginas.

Dentro de la colección de la Institución San Jerónimo, se nos presenta aquí una panorámica general de la teología petrina neo- y postneotestamentaria. S. 
Guijarro y Miguel de Burgos ofrecen una visión sintética de la teología y tradición petrina en el Nuevo Testamento. El estudio de $\mathbf{M}$. de Burgos es el que ofrece, a mi juicio, un mayor interés por su buen conocimiento de los problemas y la ponderación de sus juicios. Las teologías de los evangelios son analizadas por Rodríguez Carmona (Marcos), R. Aguirre (Mateo y una introducción al conjunto de estudios), Rius Camps (Lucas y Hechos) y Oriol Tuñí (Juan). Es sugerente, como siempre, el enfoque de Rius Camps con su constante revalorización del texto occidental. Echo de menos en Mateo un análisis más detallado de la importante perícopa de Mt 16, 16-18, así como de la abundante bibliografía que existe sobre el pasaje.

El corpus paulino (F. Pastor Ramos), las cartas de Pedro (J. Cervantes), los apócrifos no gnósticos (M. Rodriguez), los escritos gnósticos (G. Aranda y F. de Lucas) y la tradición judeocristiana (F. Cuenca) completan esta presentación de las tradiciones petrinas. Se ofrece un panorama general de la problemática exegética en tomo a Pedro, se diferencia el Pedro apóstol del discípulo (como el Cristo de la fe respecto al Jesús histórico) y se rechaza la tentación de una lectura armonizante que esconda los conflictos y las tensiones de los escritos. De todos modos echo de menos una mayor interacción y discusión entre los diversos estudios, que se yuxtaponen sin referencias entre sí, una mayor atención a las implicaciones dogmáticas y eclesiales de los textos, y una valoración de lo que implican estas teologías petrinas en el conjunto de intereses y condicionamientos que determinan las distintas obras del Nuevo Testamento, que, a su vez, son el contexto global de cada teología petrina.

De todos modos, se trata de un estudio actualizado y bien informado. Quizás el esfuerzo más serio de la exégesis española respecto a otras publicaciones colectivas realizadas por otras tradiciones teológicas. La diversidad de los textos, en calidad y en enfoque, no deben ocultar la actualidad e importancia de esta obra como material de consulta y referencia actualizada sobre el tema. La presentación tipográfica es excelente. Echo de menos índices de citas bíblicas y una bibliografía esencial que ayudara para estudiar algunos puntos concretos.

J. A. E.

Teología y liberación. escritura y espiritualidad. Ensayos en torno a la obra de Gustavo Gutiérrez. Tomo II, Lima: Instituto Bartolomé de Las Casas / CEP, 1990, 423 páginas.

Es de sobra conocido que uno de los más importantes, si no el más importante iniciador de la teología de la liberación, ha sido el sacerdote peruano Gustavo Gutiérrez. A los veinte años de la primera presentación de la teología de la liberación, tenida el año 1968, el Instituto Bartolomé de Las Casas-Rímac 
y el Centro de Estudios y Publicaciones (CEP) han querido hacer un homenaje a la perseguida teología de la liberación, en la persona de quien tanto ha contribuido para que la teología y la espiritualidad estén profundamente enraizadas en la realidad y den respuesta a los graves problemas que viven hoy las mayorías pobres de nuestro planeta. Con esta intención tomaron una parte de las aportaciones aparecidas poco antes en inglés, publicadas por Orbis Books con la misma intención, añadiendo otras muchas de teólogos y pensadores de América Latina, Europa, Africa y Asia, que respondieron masivamente a la invitación de contribuir con algún escrito a dicho homenaje.

El presente volumen es el segundo tomo (el primero apareció a finales de 1989 y recibió el tútulo de Teología de la liberación. Perspectivas y desafíos) de los tres programados para recoger los diferentes ensayos escritos, tal como antes he explicado, en tomo a la obra de Gustavo Gutiérrez. Recoge los artículos que abordan dos temas centrales de la teología de la liberación: la Escritura y la espiritualidad.

Se abre con la completa presentación que hace del contenido del tomo el dominico, nacido en Vietnam y miembro actualmente del Instituto Bartolomé de Las Casas-Rímac, Nguyen Thai Hop. Tras ella, siguen los artículos distribuidos en dos grandes partes: la primera, en torno a la palabra de Dios y a la liberación; la segunda, en torno a la espiritualidad y la liberación.

La lista de quienes han escrito los artículos es significativa y variada: J. Sobrino, A. F. Anderson, G. Da Silva Gorgulho, C. Mesters, M. Díaz Mateos, J. I. Alfaro, I. Gebara, E. Tamez, C. Robles Freyre, S. Torres, B. Häring. F. Zegarra, S. Rayan, N. Thai-Hop, C. de Prado, V. Codina, A. Nolan y M.J. Giblin.

También los títulos de los artículos son atrayentes: "Jesús, teología y Buena Noticia"; "Miriam y sus compañeras (Exodo 15,20)"; "La profecía durante y después del cautiverio"; "Dios será tu riqueza"; "El vidente entre los ciegos (Jn 9,1-41)"; "El cautiverio de María en el cautiverio de los pobres"; "Apuntes para leer la justificación en Romanos (1 - 3)"; "Gustavo Gutiérrez, peregrino de la esperanza"; "Itinerario intelectual y espiritual de G. Gutiérrez"; "La gratuidad como clave de una liberación no-violenta"; "Gratuidad y liberación (Sal 18,2.20)"; "Peleando en la noche"; "Domingo de Guzmán y la opción por los pobres"; "¿Una voz libre y profética?"; "Teología de la liberación y espiritualidad ignaciana"; "Teología en una perspectiva profética"; "Tomando en serio la historia de Africa: el reto de la teología de la liberación". Una lectura rápida de los títulos anteriores ya nos hace caer en la cuenta de que en el tomo están tratados los grandes temas bíblicos y espirituales relacionados con la liberación.

En un apéndice se recoge el documento por el que se concede a Gustavo Gutiérrez el doctorado honoris causa de la Universidad de Friburgo - Alemania. Se completa el tomo con un breve curriculum de cada uno de los colaboradores, 
que sirve para subrayar la importancia que cada uno de ellos tiene en su lugar geográfico y en su campo de trabajo teológico.

Es indudable que la iniciativa de escribir y de publicar estos artículos en tomo a la obra de Gustavo Gutiérrez puede ser contada entre las buenas ideas cuya ejecución servirá para apoyar al teólogo peruano, así como a robustecer la teología de la liberación, cuya máxima finalidad es la de defender la vida y la libertad de los pobres y oprimidos, los grandes elegidos del Dios de la Vida.

R.S.

L. Boff, La misión del teólogo en la Iglesia. Estella (Pamplona): Verbo Divino 1991, 148 páginas.

No nos encontramos aquí simplemente con un estudio de Boff, "la misión eclesial del teólogo", sino con un planteamiento que busca representar algunas de las posturas significativas en los actuales debates sobre el papel de la teología en la Iglesia y en la sociedad, y la relación entre los obispos y los teólogos. Se nos ofrece, por tanto, el documento "La vocación eclesial del teólogo" de la Sagrada Congregación para la doctrina de la fe, y el de "El teólogo y su función en la Iglesia" de la correspondiente comisión española. A esto se contrapone el citado estudio de Boff, la "declaración de Colonia", titulada "Por un cristianismo adulto" y firmada por un gran número de teólogos, y las reflexiones introductorias de J.J. Tamayo "Razones para disentir".

Esta contraposición de perspectivas permite captar algunas líneas fundamentales del debate actual, las diversas teologías que se discuten y la razón de algunas de las tensiones hoy existentes en la Iglesia. No cabe duda de que detrás de las distintas posturas subyace una eclesiología diferenciada y a veces difícilmente compatible, y que las relaciones entre jerarquía y teólogos se han convertido hoy en uno de los puntos en los que más se centran los conflictos eclesiales. Al lector queda el tomar postura ante razones y contrarrazones a la luz de las respectivas exposiciones y de sus respectivas argumentaciones teológicas.

J. A. E.

La Iglesia en Centroamérica. Guatemala, El Salvador, Honduras y Nicaragua. Información y análisis. Ed. Colectivo de Análisis de Iglesias en Centroamérica. México: Centro de Estudios Ecuménicos, 1991, 287 páginas.

Nos llega una nueva publicación del Colectivo de Análisis de Iglesias en Centroamérica (CAICA) en la que, como en años anteriores, se nos ofrece información y análisis de la situación vivida en el último año, en este caso 1990, en 
Guatemala, El Salvador, Honduras y Nicaragua, insistiendo especialmente en el papel jugado por la Iglesia católica en los procesos o cambios desarrollados en dichos paises.

De un modo especial, la información y análisis se refieren y se centran en las correspondientes jerarquías católicas así como en las bases de las iglesias de estos cuatro países. Respecto a la presentación bibliográfica que yo mismo hacía en el n. 23 de la Revista Latinoamericana de Teología de la información y análisis publicados en el año 1989, el libro presentado ahora manifiesta alguna variedad. De hecho, las situaciones han ido cambiando y la Iglesia católica también ha ido tomando nuevas posturas más comprometidas con la defensa de los derechos humanos, con la denuncia y desenmascaramiento de las situaciones de opresión, y con el apoyo decidido en la medida de sus posibilidades a la vía del diálogo y negociación. En los casos de Guatemala, El Salvador y Honduras, esto se ha dado tanto en la base de la Iglesia como en su jerarquía, al menos en una parte sustancial de ellas. En el caso de Nicaragua es en el que aparecen las mayores dificultades y divergencias entre la postura de la Iglesia de los pobres y la jerárquica, aunque en el informe que estoy presentando se vislumbra un cierto acercamiento entre las posturas de la base y de la jerarquía frente al nuevo sistema neoliberal.

Creo que estas informaciones y análisis publicados periódicamente por el Colectivo (CAICA) son de gran utilidad tanto para un mejor conocimiento de lo que va ocurriendo en los revueltos países del área centroamericana como para tomar conciencia de lo que ha significado, significa y puede significar la acción de la Iglesia católica, tanto en su parte más jerárquica como en su base más popular.

Le rendez-vous de Saint-Domingue. Les enyeux d' un anniversaire (1492-1992). Eds. I. Berten y René Luneau, París: Centurion, 1991, 366 páginas.

Desde la doble perspectiva del quinto centenario del descubrimiento de América y de la próxima conferencia general del episcopado latinoamericano en Santo Domingo, en octubre de 1992, se nos ofrecen aquí una serie de estudios que pretenden mostrar la realidad latinoamericana. La introducción y un extracto del martirologio latinoamericano de las últimas décadas preceden la primera sección en la que se analiza la evangelización de México (C. Rudel) y del Caribe (L. Hurbon) desde una perspectiva histórica, más informativa que de investigación. La segunda sección se centra en la celebración de Santo Domingo, dando la palabra a los pueblos indígenas (Rigoberta Menchu y M Löwy), desde los cuales se hace una evaluación sociopolítica de lo que se juega en 


\section{Santo Domingo.}

La segunda parte del estudio se centra en un análisis de la realidad actual latinoamericana: èl proceso de concientización global en Medellín y Puebla (Ch. Antoine), la aportación de los sacerdotes franceses de "Fidei Donum" (M. Tuininga), el proyecto "Palabra y Vida" y su anulación por las autoridades jerárquicas (C. Mesters y E. Valle) y tres interesantes estudios sobre el control de la Iglesia brasileña por la jerarquía más conservadora (J. O. Beozo), la significación de Haití en el contexto de la colonización francesa (G. Danroc) y el nacionalcatolicismo argentino con sus derivaciones sociopolíticas (E. F. Mignone).

La última sección está dedicada a la nueva evangelización propuesta por Juan Pablo II: se analiza la década "perdida" de los años ochenta (J. Cabrera Rivera), la opción preferencial por los pobres en los documentos de Juan Pablo II (I. Berten), el problema de las prioridades apostólicas en la evangelización de las culturas y su repercusión en la preparación de Santo Domingo (J. Comblin), el proyecto de una evangelización masiva a través de los medios de comunicación social (M. J. Hazard) y finalmente, como conclusión, un balance de la evangelización histórica (P. Blanquart) y de los desafíos que hay que afrontar (F. de Roux).

La variedad de enfoques, temas y autores hace difícil una valoración de esta perspectiva de América Latina. Quizás su mayor mérito sea el centrar las celebraciones del 92 en un contexto global, tanto histórico como actual, en el que se da preferencia a un enfoque crítico respecto al triunfalista, se da la palabra a los indígenas y se denuncia el proceso restauracionista de las altas esferas jerárquicas vaticanas y latinoamericanas. Los diversos trabajos son también una buena muestra de la vitalidad de la Iglesia y del continente latinoamericano, asi como de la importancia de la Conferencia de Santo Domingo, sea como confirmación del sendero trazado en Medellín y Puebla o del cambio de rumbo que se advierte actualmente a nivel de Iglesia universal.

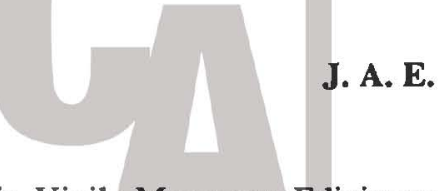

El "kairós" en Centroamérica. Ed. José María Vigil. Managua: Ediciones Nicarao / CAV / CIEETS, 1990, 170 páginas.

Coordinado por José María Vigil y con la participación de Alex Bhiman, Pedro Casaldáliga, Frank Chikane, Robert McAfee Brown, Albert Nolan, Jorge Pixley, Pablo Richard, Richard Shaull y algunos colectivos y comunidades de Guatemala, El Salvador y Panamá, nos ha llegado el libro que ahora presento.

Lo central đel mismo es la publicación del documento "Kairós centroamericano", publicado por representantes de toda la región el día de pascua del año 
1988. En dicho documento lo que se quiere manifestar es que para Centroamérica la hora que se está viviendo es un "kairós", un paso de Dios, "una oportunidad de gracia por la que el Señor nos convoca a asumir los desafíos de esta hora histórica", como nos dice en su presentación el coordinador de la obra, José María Vigil. El análisis de la realidad y el de lo que parece que Dios quiere que se haga con dicha realidad, para que sea transformada profundamente, son los dos pilares sobre los que se fundamenta el documento, como expresión que desea ser de la experiencia histórica vivida por los pueblos pobres de Centroamérica y de la esperanza que genera praxis en dichos pueblos pobres.

Tras una introducción que consiste en una entrevista a Pedro Casaldáliga -en la que va explicando qué significa el concepto "kairós" y la relación entre dicho significado y lo que está ocurriendo en Centroamérica - siguen seis capítulos cuyo contenido paso a explicar rápidamente. En el primero, varios artículos se centran especialmente en explicar en qué consiste el método teológico "kairós" y cómo dicho método tuvo su inicio en junio de 1985, en el contexto del apartheid sudafricano. E1 segundo, titulado "El kairós de Centroamérica", presenta diversos documentos, más o menos breves, elaborados en los diferentes "kairoi" centroamericanos: el guatemalteco, el salvadoreño, el nicaragüense, el costarricense, el panameño (sólo falta el hondureño), y acaba con un artículo en que se hace la pregunta de si Centroamérica no es un "kairós" para Estados Unidos. El tercer capítulo se centra sobre la perspectiva teológica del documento "kairós" centroamericano, presentándonos el contexto teológico de la crisis centroamericana, la presencia de la Biblia en el documento y algunas cuestiones discutidas en torno al mismo. En el cuarto capítulo se presenta la perspectiva pastoral de la solidaridad del documento, para pasar a continuación, en el quinto capítulo, a la publicación del documento mismo. Buenos complementos resultan los apéndices del sexto capítulo sobre las diferentes ediciones hasta el momento del documento y dos reacciones: la más negativa, la de un asesor teológico de una alta jerarquía eclesiástica, y la más fraterna, la de un colectivo de cristianos de la ex República Democrática de Alemania. Se cierra el libro con el significativo epilogo de Pedro Casaldáliga "A pesar de todo, el reino avanza".

La lectura de esta presentación del "kairós" centroamericano es un reto a no dejarlo pasar de largo, a aprovecharlo.

R. S.

R. Díaz-Salazar, El proyecto de Gramsci, Barcelona: Ed. Anthropos, 1991, 510 páginas.

Precedido por un prólogo de F. Fernández Buey, se nos ofrece aquí una síntesis del pensamiento de Gramsci centrado en su idea de la transformación de la sociedad civil (cap. 3), de la construcción de un nuevo bloque histórico en el 
que se integre el proletariado, y de la transformación del marxismo. Esta reformulación del marxismo pasa por la transformación de la crítica marxista a la religión (cap.1), por la redefinición del concepto de ideología en un sentido más neutral y positivo que el de mala conciencia (cap. 2) y por la consolidación de un Estado ético laico (Cap.4), acentuando su función educativa y la importancia del partido político como intelectual colectivo que posibilita la concientización de las masas.

El núcleo del planteamiento de Díaz Salazar lo constituye el análisis gramsciano de la religión. Desde un enfoque cronológico, se estudia la definición que propone Gramsci de religión, en estrecha correlación con el mito y con la vivencia metafísica, sus formas de organización social y de penetración popular, que constituyen un modelo "negativo" para el mismo marxismo, sus funciones sociales tradicionales y sus plataformas ideológicas, el pluralismo de las distintas corrientes religiosas y la aceptación fáctica de alianzas políticas entre marxistas y cristianos que no deben esconder el rechazo global a una falsa ideología como es la religión.

Díaz Salazar se esfuerza por revisar este planteamiento gramsciano a la luz del cristianismo liberador (cap. 5) para —desde Gramsci- intentar ir más lejos que él en su tratamiento de la religión. Desde la versión emancipatoria del cristianismo liberador revisa el inmanentismo del marxismo y del ateísmo, con una gran apoyatura en el planteamiento de Bloch y de pensadores afines, la importancia del cristianismo en la construcción actual de la izquierda y su incidencia en la transformación de la sociedad civil. Se centra de forma especial en la perspectiva italiana, analizando la evolución de los representantes del partido comunista italiano respecto de los cristianos y la revisión de algunas tesis de Gramsci. Su conclusión es la de una convergencia entre el marxismo no dogmático y el cristianismo liberador, así como el postulado de una interacción de ambos en pro de una emancipación del hombre.

Las posturas de Gramsci son sugerentes desde una perspectiva latinoamericana, ya que suponen una valoración mucho más global y positiva del "fenómeno cristiano", sin reducirlo a sus funciones sociopolíticas tradicionales, atendiendo a la incidencia del cristianismo como ideología de las masas y como organización con una mayor capacidad de incidencia en la sociedad. Sin embargo, el enfoque de Díaz Salazar es esencialmente europeo, fundamentaimente centrado en el ámbito italiano con puntuales referencias a la situación latinoamericana. Acentúa, además, la necesidad de una revisión crítica de las tesis gramscianas, aunque no procede de la misma forma en lo que respecta a la revisión de postulados y estructuras eclesiales a la luz del planteamiento gramsciano.

La crítica es, en este sentido, unilateral. Desde lo cristiano a lo gramsciano, y no a la inversa. Echo de menos un tratamiento más detallado de la religiosidad popular, así como de su ambigüedad, y también de la relación intelectuales- 
pueblo, que constituye uno de los puntos esenciales del planteamiento de Gramsci. También, en lo referente al "bloque histórico", echo de menos su análisis en correlación con las posturas ya asumidas por la tradición marxista, así como una evaluación de su concepción de las ideologías, mucho más neutral y positiva que la de Marx, en comparación con la que defienden otros autores marxistas, para ver afinidades y diferencias.

Por lo demás es un buen estudio que nos ofrece una visión de conjunto de la problemática gramsciana así como de su actualidad a la luz de la situación actual. La abundante bibliografía y referencias de las notas facilitan ampliar algunos de los puntos que trata, así como testimonian la vigencia del pensamiento gramsciano.

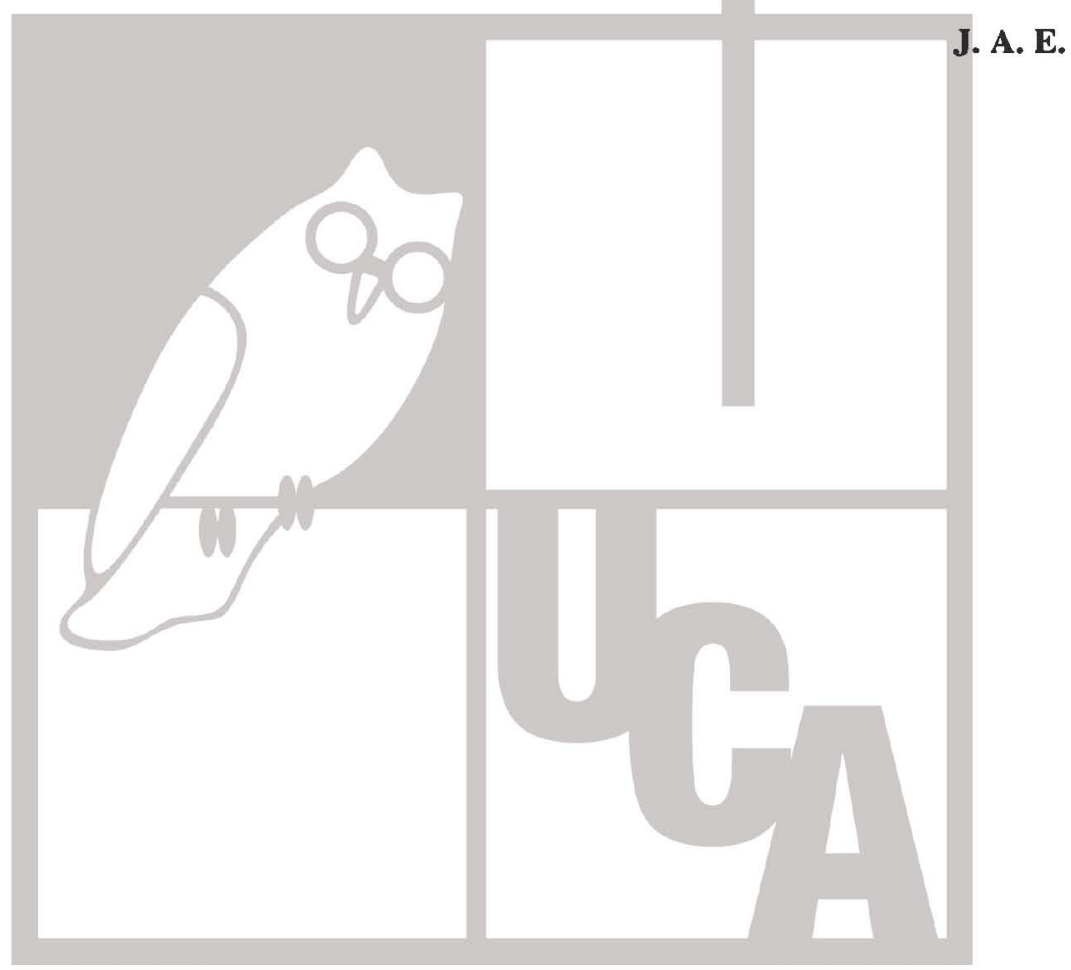

